\title{
A natureza especial da prova pericial ${ }^{1}$ \\ The special nature of the expertise proof
}

Resumo: A especialidade da perícia em relação às suas dificuldades; a perícia e a finalidade do processo: "votum" e "peritia sensu technico"; a necessidade de periciar pelo menos os autos: o objeto do
Abstract: The specialty of expertise in relation to its difficulties; the expertise and purpose of the process: "votum" and "peritia sensu technico"; the need to examine once the acts: the object of the

1 Quarta conferência proferida no II ${ }^{\circ}$ Simpósio Canônico "Questões seletas de Direito Matrimonial e Penal Canônico", promovido pelo Instituto Superior de Direito Canônico Santa Catarina em 8-9 de maio de 2018.

2 Doutor, Professor e Presidente do Institutum Utriusque Iuris da Pontificia Universidade Lateranense de Roma. Presidente, Professor e Doutor no Institutum Utriusque Iuris da Pontificia Universidade Lateranense de Roma. Recentes publicações do autor sobre o tema da conferência: com C. PEÑA, Cuestiones de derecho probatorio en Chile, Valparaíso 2014; Risultato della prova e tecnica motivazionale nelle cause matrimoniali. Casi pratici di prima istanza, Città del Vaticano 2013, 495 pp; Direito processual canônico (Trad. 5 ed.), Pegoraro, Sao Paolo 2008, 767 pp; Prova e difesa nel processo canonico di nullità del matrimonio. Temi controversi, Eupress, Lugano 2008, pp. 200; Libro VII: De los procesos. Comentario sub cc. 1400-1691; 1717-1752, in Comentario al código de derecho canónico, Edicep, Valencia 2016 (16a. ed.); La disciplina sobre el nuevo proceso brevior in SADEC, XV Jornadas anuales, Buenos Aires 2018, pp. 191- 228; El valor de las pruebas para la certeza moral de la sentencia, in SADEC, XV Jornadas anuales, Buenos Aires 2018, pp. 131-158.Buenos Aires 2018; Lo svolgimento del processo matrimoniale ordinario, in G. Dammacco (Dir.), Il nuovo processo matrimoniale canonico. Una guida tra diritto e cura pastorale, Bari 2018, pp. 18-32; Il metodo dell'utrumque ius. Ordinamento canonico e civile alla prova della giustizia. L'esempio del processo, in Monitor Ecclesiasticus CXXXII (2017), pp. 307-314; Las pruebas y su valoración en la reforma, can. 1678, en S. Sánchez Maldonado (ed.), X Simposio de derecho matrimonial y procesal canónico, Granada 2017, pp. 182-204; A orientaçâo personalista do processo canônico no CIC 1983: Dificuldades e desafios, in Suprema Lex 6 (2013) pp. 9-39. 
relatório; a avaliação da perícia direta e indireta.

Palavras-chave: Perícia. Voto do perito. Direito processual. Aquisição das provas. report; the evaluation of direct and indirect expertise.

Keywords: Expertise. Expert vote. Procedural law. Acquisition of proof.

\section{Introdução}

Para tratar da natureza especial que, a meu ver, é necessário reconhecer à prova pericial em nosso ordenamento (apesar de muitos se expressarem de tal maneira que parecem querer dizer que a perícia é uma prova como as demais) me parece mais útil recorrer à declaração que fiz na Assinatura Apostólica em 1998. O ponto que mais se apreciou de dita declaração foi a debatida questão sobre as chaves de avaliação dos informes periciais realizados somente sobre os autos. É bem sabido que a legitimidade e necessidade dos informes periciais realizados sobre os autos são discutíveis, seja por razões intrínsecas ao ordenamento jurídico da Igreja, seja também, ao menos em alguns países, por razões que derivam das leis civis e, mais diretamente, por razões deontológicas; afirma-se que as normas de ética profissional impedem os peritos de exercer seu trabalho sem contato direto com as pessoas que devem ser periciadas, ou, ao menos, sem seu conhecimento.

\section{A especialidade da perícia em relação às suas dificuldades}

Obviamente há outras razões pelas quais se pode afirmar que a prova pericial é especial. Entre elas destacam-se na atividade forense os problemas relacionados com sua credibilidade objetiva. Em relação a isso, é preciso mencionar as dificuldades de natureza científica e as de natureza jurídica, pelas quais vale a pena qualificar a natureza da perícia de forma autônoma em relação às outras provas, dando assim razão de sua natureza especial.

Assim, desde o ponto de vista jurídico, a dificuldade deriva do conflito entre dois princípios (perito in arte credendum; iudex peritus peritorum). A questão não se esgota na avaliação, mas sim em suas 
características como prova, refletidas no debate sobre a figura do perito como um misto de testemunha e juiz, debate estéril, mesmo sem chegar a sustentar que possa se configurar o perito como um assessor do juiz (no sentido de outros ordenamentos e do cânon 208).

Do ponto de vista científico, a principal dificuldade provém da credibilidade subjetiva da pessoa submetida à perícia, por sua atitude na perícia forense ser distinta daquela que se presume ter quando necessita de psicoterapia. Outra dificuldade se apoia naquilo que se pede ao profissional: iniciar com um diagnóstico aproximado para ir tratando o paciente e resolver no futuro ou, ao contrário, apurar com precisão dados referidos mormente ao passado.

A consideração autônoma permite qualificar a perícia como prova especifica por sua complexidade (conjunto de operações: examen et votum), com boa dose de autonomia do perito (segundo os métodos escolhidos), com equilíbrio entre explorações diretas e avaliações críticas indiretas, tanto dos dados explorados, como dos dados presente nos autos, de forma que sirvam a integrar os conhecimentos do juiz (justamente por serem avaliações técnicas). Daí a nota principal de colaboração (questionários) porque a lei considera irrelevantes os conhecimentos técnicos do juiz.

Uma segunda razão que converte em especial a natureza da prova pericial tem a ver com a sua avaliação, pois ainda que pertença ao grupo das chamadas provas livres, a lei e o Magistério não deixam de reclamar uma avaliação detalhada que deva se refletir nas motivações pelas quais se acolhem ou se recusam as conclusões do perito. Os três critérios de avaliação da perícia são os do fundamento metodológico, o do fundamento factual e o do fundamento antropológico. Deste último já nos ocupamos. Sobre os outros dois critérios voltarei ao final desta colocação, pondo-os em relação com as perícias realizadas somente sobre os autos. Irei me referir exclusivamente às chamadas "perícias psíquicas" por razões de utilidade, sendo nesse âmbito de onde, principalmente, se colocam os problemas e as possíveis diferenças entre perícia direta e perícia sobre os autos. 


\section{A perícia e a finalidade do processo: "votum" e "peritia sensu technico"}

A legitimidade da perícia sobre os autos, sem o consentimento do interessado, desde um ponto de vista canônico pareceria ter sido deixada de lado por possível lesão ao direito a defender a própria intimidade, direito recolhido no cânon 220 e facilmente vinculante, desde os direitos estatais e o direito internacional, até as chamadas leis sobre a "privacy", ainda que estas tenham por objeto proteger a utilização de dados e documentos sem permissão do interessado.

Não e difícil desmontar semelhante impostação, como já foi feito na doutrina, invocando-se a natureza pública do processo e dos autos submetidos à perícia. Em âmbito canônico, o direito à intimidade resulta garantido somente contra as agressões "ilegítimas" que, por definição, não se hipotiza em um processo dirigido por uma autoridade pública e de donde se ventilam questões de interesse público, ainda quando estejam relacionadas com a esfera íntima. É preciso considerar, além disso, a distinção entre a garantia do direito de defesa e o seu efetivo exercício que, nestes casos, se resultasse afetado, o seria por exclusiva e unilateral decisão daquela parte que recusa se submeter ao exame do perito. Em terceiro lugar, a perícia sobre os autos está justificada pelo idêntico respeito que merecem os direitos da outra parte e pela natureza não exclusivamente pessoal dos direitos submetidos à investigação do perito e ao debate judicial, como ocorre nas causas de nulidade matrimonial.

Em última instância, a legitimidade da perícia sobre os autos deriva da finalidade do processo que não é outra que a descoberta da verdade e que obriga a interpretar com amplitude o conceito canônico de "prova lícita", contemplado no cânon 1527 que, a respeito de seu paralelo no código anterior, contem uma dicção nova, nem sempre valorizada com suficiente atenção na doutrina e na práxis. Com efeito, a simples "significatio verborum" demonstra a irrenunciável prevalência que hoje merece o "favor veritatis" na hora de estabelecer a licitude dos meios de prova e de comprovação dos fatos, adivertindo, como pressuposto básico, que no processo canônico se admitem probationes cuiuslibet generis". 
A licitude, portanto, nada tem a ver com o elenco de provas codiciais, isto é, com as chamadas provas "típicas". O "favor veritatis" aceita a admissão, sem diminuição da licitude, de provas atípicas. Por isso, sustento sempre que o critério de licitude de prova não se relaciona diretamente com as modalidades que se obtêm, nem com o possível conflito com outros direitos (como o direito à propriedade de um documento) que cede sempre diante do direito superior a esclarecer o próprio estado de vida. A licitude se relaciona somente com o respeito à dignidade (que não da intimidade) das pessoas e dos valores eclesiais e evangélicos que subjazem a ela.

Isso resolve a mais superficial das objeções contra a legitimidade da perícia sobre os autos, isto é, que o código não o previa expressamente. Se algo caracteriza o ordenamento canônico é justamente o não ser um direito somente positivo, que se fundamente na letra da lei escrita, positiva e promulgada. Em qualquer caso, a mesma lei positiva recolhe esta possibilidade, já citada no c. 1527 , e no c. 19 , que estabelece, para os casos de "lacuna legis", proceder segundo a práxis constante da cúria romana. Em âmbito judicial, essa práxis é a do Tribunal Rotal que, desde tempo imemorial, procede deste modo, não só quando nomeia um super-perito para analisar as perícias realizadas por outros, mas também quando confia a um profissional o estudo exclusivo dos autos.

Na realidade, o vigário geral que levantou o problema à Assinatura nunca duvidou que a perícia sobre os autos fosse canonicamente legítima. Seu problema era a provável impossibilidade de contar no futuro com peritos dispostos a realizar esses relatórios, depois que o colégio de médicos do lugar expulsou a um deles, entre outras coisas, por ter procedido sem contato direto com o periciado. A deontologia dos profissionais da medicina, em geral, parte da intangibilidade do direito à intimidade.

Todavia, convém sublinhar que nem das legislações civis modernas e nem dos códigos de ética profissionais é possível extrair uma relação tão automática, como pode parecer, entre o respeito da "privacy”, a que estão sujeitos os sociólogos e psiquiatras, e o trabalho que a estes pode ser requerido de periciar os autos em um processo sem consentimento expresso do interessado. Vice-versa, as leis sobre 
a "privacy" protegem sobremaneira a divulgação a terceiros de documentos pessoais sem a devida permissão (com algumas variantes e distinções no que diz respeito a sua produção em juízo). A expulsão do perito em questão ocorreu mais por uma imprudência em relação à divulgação e somente indiretamente devido à realização do relatório sobre os autos, que o tribunal médico criticou, sobretudo, por não ter sido interpelado o interessado e por se ter deduzido sua ausência no juízo como uma negativa à perícia direta.

Portanto, o principal problema da perícia sobre os autos não é o caráter legal, nem foi isso que moveu a Assinatura que só dedica um número ao tema. O Supremo Tribunal, ao invés de resolver o caso específico com outras medidas, aproveitou a ocasião para abordar o verdadeiro problema que surge em semelhantes circunstâncias, isto é, a relação entre a certeza moral, requerida para decidir as causas de incapacidade, e a prova pericial. Nesse contexto se compreende que a dificuldade da ação pericial sobre os autos é do tipo técnico, pois a perícia deve ser realizada, como estabelece o c. 1574 "praeceptis artis vel scientiae innixum", o qual exige normalmente o exame direto do periciado. Mas uma coisa é o valor de um relatório realizado somente sobre os autos, outra coisa muito distinta é a sua licitude como meio de prova.

Advirto que ao configurar a ação pericial sobre autos como " $\mathrm{vo}$ tum" e não como "peritia sensu technico", pode parecer que a Assinatura estaria querendo remarcar a diferença de valor que existe entre eles. Nada mais longe da realidade, pois a diferença é evidente, tanto nas vantagens como nos inconvenientes. Ademais, a mesma perícia técnica não tem alcance de prova legal senão de livre apreciação. Posso assegurar que o que moveu a Assinatura a classificar como "votum" a ação pericial sobre os autos foi principalmente (para não dizer exclusivamente) o desejo de tutelar, em âmbito extra canônico, o trabalho do perito chamado a intervir nessas circunstâncias. A Assinatura, através das consultas pertinentes, deve entender que, no âmbito profissional, ainda que seja discutível (e até reprovada) a realização de uma perícia técnica sem contato com a parte, não merece idêntica reprovação que profissionais emitam um parecer, com todas as cautelas do ca- 
so, e que, no processo canônico, se diga que tal parecer possa resultar, não só suficiente, mas imprescindível.

\section{A necessidade de periciar pelo menos os autos: o objeto do rela- tório}

Não podemos, pois, adentrar no tema da avaliação dos relatórios periciais, sem tratar de antemão, de acordo com o que foi o motivo principal da declaração da Assinatura, o problema da necessidade da prova pericial. Mas, em concreto, perguntamo-nos se o Supremo Tribunal, pela exigência de assegurar a requerida certeza moral nas decisões judiciais, pretendeu declarar que, nas causas de incapacidade psíquica, é necessário periciar, ao menos, os autos, exceto na hipótese de evidente inutilidade prevista pelo cânon 1680 . No caso de resposta afirmativa, vistos os limites metodológicos que implica a falta de exploração direta, resultará também mais claro qual pode ser o objeto essencial do parecer do perito e o valor de sua contribuição, isto é, aquele que não poderia ser conhecido pelo juiz, com suficiente objetividade, sem a ajuda de um especialista em ciências psíquicas que analise, pelo menos, os autos.

Sobre a primeira questão, isto é, se a Assinatura pretendeu esclarecer que nas causas de incapacidade, com a exceção estabelecida no cânon 1680, é necessário periciar, ao menos, os autos, a resposta pode parecer negativa, de acordo com o texto da declaração, em concreto, pelo significado literal de suas palavras. No número 6 do documento, o Supremo Tribunal se limita a constatar que, quando uma parte recusa a perícia, o juiz pede o parecer do perito sobre os autos. Baseandose na análise textual, Don Manuel Calvo Tojo afirma que "fica suprimida a perícia obrigatória somente sobre os autos", acrescentando que a Assinatura, limitando-se a referir essa prática, "de modo algum... manda continuá-la ou sugere mantê-la".

Tendo presente os critérios hermenêuticos das normas canônicas, o significado literal é apenas o primeiro, com a peculiaridade de não poder ser separado do contexto, da finalidade (ratio legis) e da intenção do legislador (mens legislatoris). Não se está diante um texto legislativo em sentido estrito, pois a Assinatura não tem poder legisla- 
tivo; porém, os critérios para interpretar suas disposições, que têm valor normativo próprio de quem exercita um poder administrativo universal, são os mesmos critérios estabelecidos para interpretar as leis. Para interpretar, portanto, este documento, há que se considerar, além do texto, o contexto, sua finalidade e a intenção de seu autor.

Da utilização de todos estes critérios, não só não parece que a Assinatura tenha suprimido a perícia sobre os autos, mas justamente fez o contrário. Comparando o citado número $6 \mathrm{com}$ seu contexto mais imediato (o anterior número 5), resulta clara a distinção de situações que se abordam. No número 5 trata-se de situações nas quais não é necessária a perícia; a Assinatura torna explícito o alcance da "evidente inutilidade" da perícia psíquica, reduzindo a hipótese prevista no cânon 1680 a dois casos: a existência de um documento ou de um testemunho qualificado; ou a existência irrefutável de fatos e circunstâncias que, sem margem de dúvida razoável, confirmem as distintas hipóteses de incapacidade previstas no cânon 1095, ainda sem um diagnóstico detalhado sobre a causa psíquica que provoca a referida incapacidade. Note-se que, inclusive nestes casos, ainda sem ser necessária a perícia, prevê-se que o juiz possa pedir explicações a um perito sobre o significado de algum documento ou fato contido nos autos.

Pelo contrário, no sucessivo número 6 , a situação que se aborda é aquela na qual a perícia é necessária, porém resulta impedida pela recusa da parte a ser periciada. Visto quanto afirmado no número imediatamente anterior, trata-se dos casos nos quais não existem documentos ou testemunhos qualificados sobre a incapacidade e daqueles outros em que os fatos coletados nas demais provas não permitem conhecer, com a devida certeza, não mais o diagnóstico (que em si não é necessário em vistas a decidir sobra as diversas formas de incapacidade), e nem mesmo o que a Assinatura chama de "verdadeira natureza" dos possíveis defeitos psíquicos detectados nas demais provas, de modo que, sem a perícia de um especialista, que analise ao menos os autos, não seja possível alcançar a certeza moral judicial sobre a incapacidade, com a objetividade requerida para isso.

Chegamos, assim, ao ponto crucial de nossa análise, a saber, a finalidade do documento que nos ocupa e a intenção de seu autor, critérios estes que nos permitem afirmar que a Assinatura, nos casos ci- 
tados, não só dá clareza à legitimidade das análises periciais sobre os autos, senão que adverte a possível necessidade do mesmo se a parte recusa a perícia direta. Foi a exigência de reiterar alguns princípios (como se lê no preâmbulo) que levou a Assinatura a fazer esta declaração. O princípio fundamental vem exposto no primeiro número e não é outro que esclarecer o necessário suporte objetivo (e não só subjetivo) da certeza moral do juiz, pontuando (nos números 2, 3 e 4) a fonte de que provém esta base objetiva nas causas de incapacidade; posto que nestas há que se estabelecer a condição psíquica do alegado incapaz no momento do matrimônio, se afirma que a base objetiva vem da perícia (2).

À finalidade do documento há que adicionar a intenção específica do autor, que descobrimos analisando sua origem concreta, isto é, a pergunta de um vigário judicial sobra a possibilidade do juiz alcançar a certeza moral "ex propria scientia non professionali", e, portanto, que possa prescindir da perícia, não só quando resulte inútil, senão também quando o trabalho do perito no foro eclesiástico resulte moralmente impossível. A Assinatura reitera que só a evidente inutilidade "ex adiunctis" permite prescindir da obra do perito, e não a "scientia non professionali" do juiz (n.3); se acrescenta que a exigência de realizar a perícia, para alcançar a base objetiva da certeza moral, não deriva só de uma prescrição legal, senão da natureza das coisas, isto é, da incapacidade psíquica na qual se funda a incapacidade jurídica que, obviamente, só um especialista pode estabelecer (n.4). Vejamos ainda estas duas razões.

Sobre a prescrição do cânon 1680, que impõe a perícia nas causas de incapacidade, exceto quando a perícia "ex adiunctis evidenter inutilis appareat", advertimos que não é uma lei irritante, segundo o cânon 10. A sentença emitida nestes casos, sem previa perícia, não seria (por essa razão) uma sentença inválida. Visto o motivo que aduziu o vigário judicial, isto é, a eventual impossibilidade de recorrer em sua nação à perícia sobre os autos, a obrigatoriedade da perícia seria ainda menos clara pela prevalência, ante uma norma de direito positivo (o cânon 1680), de um princípio de direito natural: "ad impossibilia nemo tenetur". Contudo, a questão decisiva não é meramente processual, mas, substancial. Não só a Assinatura, mas, a qualquer operador 
da justiça na Igreja, o que mais lhe interessa verificar não é se a impossibilidade de obter a perícia permite uma legítima violação do c.1680. O que importa é se, nesses casos, apesar de que a perícia resultar "ex adiunctis" necessária, o juiz pode sentir-se autorizado a pronunciar sentença afirmativa com a suficiente certeza moral, pois já se sabe que sem a devida certeza a sentença deve ser pronunciada "pro vinculo". Que o juiz possa "ex adiunctis" alcançar certeza sem a ajuda de peritos nada tem a ver com a impossibilidade de obter essa prova; se a ajuda do perito resulta "ex adiunctis" necessária, a impossibilidade de obter a perícia não permite diminuir as exigências da certeza moral nem ameniza a obrigação de evitar a probabilidade de erro, decidindo afirmativamente sobra a incapacidade.

O limite entre probabilidade e certeza na comprovação dos fatos de natureza psíquica nos introduz na segunda razão aduzida pela Assinatura para justificar a exigência da perícia, isto é, a natureza das coisas que deve ser averiguada antes de pronunciar-se sobre a incapacidade jurídica. Às vezes se peca por defeito e se considera inútil o trabalho do perito porque parecem suficientes os resultados das demais provas sobre os comportamentos anômalos. Porém, a equivalência entre comportamentos anômalos e incapacidade não tem base científica em psicologia, como tampouco a tem na doutrina forense, e menos ainda na doutrina do Magistério que recorda, para este tipo de causas, a exigência de ultrapassar o horizonte fenomenológico (o dos comportamentos), e adquirir certeza sobre as causas e processos psicodinâmicos que subjazem a tais condutas. Nos discursos à Rota, nos anos de 1987 e 1988, o Papa expunha esta exigência aos próprios peritos, exortando-lhes a evitar as chamadas "perícias meramente descritivas" dos sintomas.

Às vezes se peca por excesso e se considera impossível pronunciar-se sobre a incapacidade sem prévio diagnóstico, confundindo a respeito da incapacidade canônica, os conceitos de anomalia, psicopatologia e enfermidade mental. É certo que o enquadramento diagnóstico, fruto de uma aproximação descritiva, não é suficiente, porém, também é certo que o enquadramento em uma etiqueta diagnóstica não é necessário, contanto que "ex adiunctis" resulte provada "evidenter" a existência de uma situação psíquica deficitária (ainda não defi- 
nida em categorias científicas) e resulte clara sua conexão com a possibilidade de fazer-se cargo das obrigações conjugais. Então, não é necessária a perícia.

Em definitivo, desde a base objetiva em que deve sustentar-se a certeza moral, a perícia resulta necessária, ainda que seja impossível obter uma perícia técnica, se os autos, ainda pondo em evidência lacunas na personalidade e comportamentos anômalos do alegado incapaz, no consentem estabelecer a existência de uma anomalia psíquica ou a conexão entre esta e as capacidades requeridas para o matrimônio. A Assinatura, quando a parte recusa a se submeter à perícia direta, caso seja necessária, aponta para a possibilidade de se alcançar a objetividade requerida, recorrendo-se ao parecer de um especialista que analise os autos.

A alternativa é não poder decidir afirmativamente sobra a incapacidade. Por isso creio que o número 6 do documento da Assinatura responde a outro princípio, não mais de direito matrimonial substancial, mas dos chamados direitos fundamentais dos fiéis, entre os quais se incluem a eleição do estado de vida (cânon 219) e a tutela judicial (cânon 221). Algum autor de reconhecido prestígio, comentando esta declaração, o põe em dúvida, porém cabe pensar que a Igreja, por razões alheias a sua responsabilidade (como seria a impossibilidade de obter em certos países a colaboração de peritos dispostos a examinar somente os autos) se renda e faça uma exceção em seu sistema de garantias, deixando sem acolhida as justas reclamações dos fiéis. Se a impossibilidade de superar a probabilidade de erro, ainda quando seja inculpável e atribuível ao obstrucionismo de uma parte, impõe ao juiz a obrigação de decidir "pro vinculo", a probabilidade de cometer grave injustiça com a outra parte lhe consente prover, inclusive de ofício (cânon 1452), a superar as lacunas probatórias com meios adequados. Um deles é o parecer do perito sobre os autos, para que sustente o que o juiz "ex adiunctis" (e não por sua experiência subjetiva) não pode sustentar com objetividade.

Recorde-se que nos referimos à objetividade própria do conhecimento científico que, ainda segundo o nível próprio de cada tipo de saber, é sempre diverso do conhecimento pré-científico, caracterizado por sua base intuitiva e subjetiva. Se a lei impõe ao juiz submeter ao 
exame de um especialista determinados fatos é porque, sobre eles, não reconhece ao órgão judicial um conhecimento objetivo, mas, subjetivo e, como tal, irrelevante. A irrelevância é estabelecida por imperativo legal, prescindindo de sua efetiva correspondência com os reais conhecimentos científicos do juiz. Requer-se, pois, que entre os autos haja elementos objetivos, cientificamente fundados, sobre os fatos psíquicos que sustentam os fatos jurídicos. O parecer do perito, ainda centrado somente nos autos, permite passar do conhecimento subjetivo do juiz, baseado na experiência, ao conhecimento objetivo ou crítico, baseado nas leis da ciência, que não julga os fatos tal qual aparecem ao observador, aplicando o critério da semelhança, mas que estabelece a relação dos fatos tendo por base classificações universais; por isso as ciências psíquicas, ainda sem serem exatas, produzem dados objetivos e verificáveis.

Relacionando os diversos argumentos tratados pela Assinatura podemos indicar três conclusões sobra a necessidade e o objeto da perícia sobre os autos: a primeira é que pode ser solicitado o parecer de um perito mesmo nos casos em que, pela existência de um documento, de um testemunho qualificado, ou de fatos irrefutáveis, não seja necessário realizar a perícia técnica; nesse caso, o perito se limitará a esclarecer o significado do que foi colhido, sem necessidade de estabelecer um diagnóstico preciso, em quanto o elemento a esclarecer resultará em si mesmo certo, tanto em sua qualidade de defeito psíquico, quanto em sua evidente conexão com a incapacidade matrimonial; a segunda conclusão é que não só se pode, mas, deve-se solicitar o parecer de um perito quando, por carência de algum dos referidos elementos, resulte necessária a perícia técnica e esta não pode ser realizada pela recusa do alegado incapaz; disso se depreende a terceira conclusão, a saber, que o objeto deste parecer não será esclarecer o significado de algum aspecto relativo a defeitos psíquicos certos e conexos com a incapacidade matrimonial, mas sim estabelecer, interpretando os fatos com critérios científicos, se se pode atribuir a estes a qualificação de fatos estruturalmente anômalos e qual seria a sua conexão com as capacidades matrimoniais. 


\section{A avaliação da perícia direta e indireta}

Esta última conclusão é a mais importante e nos permite entrar já de cheio na avaliação da perícia sobre os autos, entendendo o conceito de avaliação no sentido estrito. $\mathrm{O}$ que há de avaliar e os critérios para fazê-lo, estão em relação direta com o que cabe esperar de um parecer sobre os autos, isto é, estabelecer desde pressupostos científicos (que o juiz não possui ou que a lei não o reconhece) se os fatos recolhidos na instrução da causa podem ser considerados defeitos psíqui$\cos$ e que entidade cabe atribuir-lhes em vista à formação da decisão matrimonial e à condução da vida conjugal. Assim, se deduz do n. 6 da declaração da Assinatura, quando estabelece que, nestes casos, ao perito "potest ut exponant momentum huiusmodi voti ad veram defectus psychici naturam dignoscendam". Se ao perito deve-se pedir que se esforce para mostrar o fundamento do seu parecer, indicando o seu valor tendo em vista o conhecimento da real natureza do defeito psíquico, posto que ele não terá outros elementos além dos autos, se é obrigado a deduzir que a Assinatura está se referindo ao fundamento científico, isto é, à relação que cabe estabelecer entre os fatos históricos recolhidos no processo, sua conexão interna e sua relevância psíquica, utilizando os habituais critérios de avaliação da psicologia e da psiquiatria.

Pondo em relação cada um desses pontos com os quais, na doutrina mais comum normalmente indica-se como critérios da avaliação da perícia direta, se esclarece principalmente seu alcance e talvez resulte mais evidente a razão científica, e não só a razão de mera oportunidade (à qual já nos referimos) pela qual o parecer sobre os autos se configura como "votum" e não como uma perícia no sentido técnico. Esta última se separa claramente da perícia sobre os autos; porém, a referida distinção se inscreve unicamente no pressuposto metodológico e não, ao menos não diretamente, nos pressupostos de avaliação científica. Por ele, desde o ponto de vista estritamente processual, como já tive oportunidade de advertir em outro lugar, a perícia direta é, ao mesmo tempo, uma prova direta e histórica, sem perder sua condição de prova prevalentemente indireta e crítica. O c. 1574 adverte sobre esta dupla condição da prova pericial, indicando seu duplo momento: 
"examen et votum". É prova direta e histórica porque o perito, examinando a parte com o colóquio clínico ou com as distintas técnicas de exploração, produz sempre fatos novos, que em si não estavam incluídos nos autos e que, segundo os casos, podem requerer ulterior comprovação judicial. Não vou agora repetir a crítica, que em outros momentos fiz, dessa ideia generalizada, para mim precipitada e pouco matizada, segundo a qual se devem rejeitar plenamente as perícias fundadas em fatos não comprovados nos autos. Contudo, embora a perícia técnica produza fatos históricos novos, embasados em uma percepção direta da realidade, a maioria das afirmações do perito, ainda as relacionadas com esses fatos, coletados do contato com a parte, são fruto de raciocínios e avaliações indutivas, julgando seu alcance, com parâmetros científicos que o juiz não possui. Por isso a perícia é, sobretudo uma prova indireta ou crítica, finalizada para integrar os conhecimentos do juiz, produzindo deduções científicas que, enquanto tais, constituem sempre uma novidade entre os materiais probatórios e que, nas causas de incapacidade, são necessárias para alcançar, com base objetiva, a certeza moral.

Neste segundo aspecto, isto é, em sua condição de prova indireta e crítica, a distinção entre a perícia técnica e a perícia sobre os autos é encurtada; em ambos os casos, o juiz deve avaliar a solidez científica das deduções do perito, sem prejuízo de que tais deduções indiretas e científicas, quando o perito conseguiu examinar a parte, tenham maior fundamento na realidade por aproximar-se dela com mais garantia de método. É justamente este o primeiro parâmetro de avaliação da perícia técnica, seu fundamento metodológico, que o juiz deve examinar com os olhos de um leigo, descobrindo o equilíbrio entre os dados recolhidos nas técnicas investigativas utilizadas pelo perito e nas deduções globais de natureza científica, comparando-as com as noções de medicina legal que o juiz deve conhecer. No caso do "votum" não há lugar para a avaliação do pressuposto metodológico.

Da perícia técnica cabe esperar mais em relação ao que a Assinatura chama "verdadeira natureza" da disfunção. Permanece de pé, ainda na perícia direta, que não é necessário, embora seja conveniente, que o perito tenha um diagnóstico preciso, que como tal não se requer para estabelecer a incapacidade jurídica. Mas a definição diagnóstica é 
um passo convencional no campo da psicologia e da psiquiatria, pelo que o perito deve esforçar-se em formulá-la.

O que interessa, com ou sem diagnóstico, é que o perito explique a natureza, a origem, a evolução, a gravidade e as repercussões das disfunções do alegado incapaz, o que é muito mais arriscado ainda que a formulação de uma hipótese diagnóstica. Quando tem o contato direto com o interessado, o perito possui maiores possibilidades de apurar esses dados e formular um diagnóstico, confrontando os resultados de seu exame com os resultados dos autos. Sem este contato, as possibilidades de dar resposta a todas essas questões estão à mercê da qualidade da instrução da causa, que deverá ser realizada com precaução, para que o perito, ao oferecer seu parecer, não encontre lacunas referente aos pontos sobre os que se deve pronunciar em termos científicos. Em qualquer caso, o perito que deve se limitar a examinar aos autos, é melhor que conclua sua análise sem fazer uma precisa formulação diagnóstica, limitando-se a dar as respostas pertinentes sobre as questões indicadas, na medida em que os dados da causa o permitam.

Por isso, mais que uma anomalia precisa, o perito pode referir-se à organização das estruturas psíquicas, trazendo uma nova luz (de valor científico) sobre os déficits da personalidade que emergem dos autos, qualificando tais deficiências em termos categoriais e estruturais desde a conexão que cabe estabelecer entre os dados existentes. A abordagem estrutural e psicodinâmica garante o fundamento antropológico da mesma perícia direta, segundo parâmetro de avaliação, que permite assegurar-se de que o perito não tenha realizado uma apressada soma de sintomas anômalos, formulando um diagnóstico em chave determinista, sem a devida consideração do papel que cabe atribuir ao esforço, aos recursos morais e transcendentes na superação das deficiências e dificuldades. Depois dos discursos papais dos anos 1987 e 1988 não deveria faltar nas sentenças uma menção explícita sobre o correto fundamento antropológico da perícia, ou, ao menos, se se acolhem as conclusões, sobre a falta de objeções desde o ponto de vista antropológico.

A diferença do fundamento metodológico, o fundamento antropológico sim que deve ser levado em conta na avaliação perícia sobre os autos; porém, se deve fazer uma particularização sobre o modo de 
avaliar o dito fundamento com relação às perícias diretas. A falta de contato direto, ainda quando a instrução tenha sido realizada com o maior cuidado, pode provocar que o perito não se atreva a responder aos temas da "origem" e da "evolução" das deficiências com demasiada precisão; e não deve aventurar-se a fazê-lo se não tem dados suficientes; basta que o reconheça honestamente, pois isso não vai comprometer radicalmente a utilidade judicial de seu parecer desde o ponto de vista antropológico. E mais, justo porque a falta de contato direto não permite formular um diagnostico preciso, que implica já uma hipótese sobre a etiologia e o desenvolvimento de cada tipo de anomalia, a necessidade de ater-se a uma avaliação global e estrutural converte a avaliação do fundamento antropológico do parecer do perito naquele que este tem de mais genuíno e necessário, isto é, esclarecer o grau de voluntariedade dos comportamentos anômalos e sua incidência no âmbito do pensamento, da autodeterminação, da afetividade, da oblatividade, da integração sexual, da responsabilidade, etc.

À diferença do que ocorre com as perícias técnicas, onde a exploração direta e a possibilidade de fazer um diagnóstico oferecem elementos novos capazes de responder a origem e ao desenvolvimento psicodinâmico das disfunções, no caso do modo pericial sobre os autos, essa mais modesta avaliação dos dinamismos que escapam à voluntariedade do sujeito não terá outra justificação que os dados obtidos nas demais provas. Com ele chegamos ao terceiro critério da avaliação do modo pericial, talvez o mais decisivo e o mais evidente desde a posição que ocupa o juiz; trata-se do fundamento fático. Se sobre o fundamento metodológico o juiz deve avaliar a perícia com os olhos de um leigo, e se sobre o fundamento antropológico a avaliação pode limitar-se a constatar a inexistência de objeções de corte determinista, sobre o fundamento fático e aderência aos autos a avaliação deve ser exaustiva e pontual, de modo que nenhuma das afirmações do perito resulte em contradição líquida com os atos recolhidos nas declarações.

\section{Conclusão}

Pois bem, em relação ao fundamento fático, como advertiu Mons. Serrano em sua colocação de 1987, o exame dos autos tem 
maiores garantias ainda que a perícia direta, por não ser uma prova histórica e direta, mas apenas crítica e indireta. Que a perícia sobre os autos seja mais segura sobre o fundamento nos dados da causa, não significa que a perícia técnica, com sua investigação direta, não seja mais segura sobre as reais condições psíquicas do sujeito, ainda quando se apoie em fatos não totalmente contidos nas demais provas. $\mathrm{O}$ que ocorre é que esses fatos novos necessitam de ulterior comprovação judicial, seja na ratificação da perícia (que já não é obrigatória, mas sobre cuja reavaliação vale a pena discutir), seja convocando de novo as partes ou às testemunhas, quando os fatos novos nos quais se fundam a perícia direta, não só estejam suficientemente contidos nos autos, mas que resultam em contraste com os dados recolhidos neles.

Com o dito sobre o tríplice fundamento de qualquer perícia, creio que resulta manifesta a diferença entre a avaliação da perícia técnica e a perícia sobre autos, e pode-se compreender o alcance do que a Assinatura adverte no n. 6 de sua declaração, isto é, que o "votum" do perito "diversimode ac peritia sensu technico... aestimandum est"; com efeito, considero que além de tutelar aos peritos em âmbito extra canônico, essa advertência manifesta que os resultados de uma e de outra perícia incidem no processo e na comprovação da incapacidade psíquica, anterior à decisão, de forma diversa. É certo que não há regras de avaliação que permitam considerar a perícia técnica como prova legal, mas livre; mas sua contribuição, em vistas de descobrir a incapacidade, é maior e se põe acima da reconstrução dos fatos, seja para implementar ainda a investigação judicial dos mesmos, seja para dar início à motivação, que deve partir da situação psíquica do alegado incapaz, pois a perícia técnica pode estabelecer a mesma com garantias inclusive diagnósticas.

$\mathrm{O}$ voto do perito sobre a situação psíquica do alegado incapaz não é um ponto de partida, mas de chegada, não só porque, a princípio, da dita opinião não cabe esperar que devam efetuar-se ulteriores comprovações, mas porque como tal parecer, em vistas a descobrir a incapacidade psíquica, o voto do perito não é prova autônoma que possa produzir, com os habituais instrumentos técnicos, um diagnóstico. O voto trará só os necessários esclarecimentos sobre o alcance estruturalmente anômalo das deficiências da personalidade que emer- 
gem das outras provas, explicando sua raiz profunda, sua voluntariedade ou involuntariedade, sua entidade e sua incidência ou conexão com o funcionamento das faculdades psíquicas que cabe exigir em vista da deliberação e ao desenvolvimento da vida conjugal. Portanto, o esquema de motivação deve ser também diverso; não seria lógico (nem conveniente) por no vértice do silogismo probatório, mas em sua conclusão, o parecer do perito. Sugiro, pois, que sejam seguidos uns esquemas de motivação da sentença, distinguindo os casos nos quais a comprovação tenha podido efetuar com a perícia direta e aquelas nos quais se há devido proceder somente com o voto do perito sobre os autos. No primeiro caso se deve partir das conclusões do perito e justificar sua acolhida ou rejeição segundo seu fundamento metodológico, antropológico e fatual. No segundo caso se deve partir dos fatos e concluir com o parecer pericial.

\section{Bibliografia}

A. Stanckiewicz, La configurazione processuale del perito e della perizia nelle cause matrimoniali per incapacità psichica, in Quaderni Studio Rotale 5, 1990, 57-66.

B. Gianesin, Perizia e capacità consensuale nel matrimonio canonico, Padova 1989.

B. Lonergan, Insight: a study of human understanding, London 1958.

C. Lefèbvre, De peritorum iudicumque habitudine in causis matrimonialibus ex capite amentiae, in Periodica de re morali canonica liturigica 65, 1976, 109.

E. Montaigne, Expertisse, in Dictionnaire de droit canonique 5, Paris 1953, 703.

G. Versaldi, L'oggettività delle prove in campo psichico, Brescia 1981, 192-193.

Gramunt-Wauck, Moral certitude and the collaboration of the Court Experts in cases of consesual incapacity, in Studia Canonica 20, 1986, 77. 
J. J. Garcia Failde, Manual de psiquiatria forense canonica, Salamanca 1991, 159.

J. M. Serrano, Características y valoración jurídica de la pericia psiquica en los tribunales eclesiásticos a la luz de los discursos de S.S. Juan Pablo II. In Curso de derecho matrimonial y procesal canónico para profesionales del foro 8, Salamanca 1989, 293.

J. M. Serrano, La perizia nelle cause canoniche di nullità matrimoniale, in Perizie e periti nel processo matrimoniale canonico, Torino 1993, 88.

J. Martín de Agar, Giudice e perito a colloquio, in L'incapacità di assumere gli oneri coniugali, Città del Vaticano 1998, 191.

L. Del Amo, Valoración jurídica del peritaje psiquiátrico sobre neurosis, psicopatias y trastornos de la sexualidad, in Ius Canonicum 22, 1984, 662.

M. J. Arroba Conde, Direito processual canônico (Trad. 5 ed.), Pegoraro, São Paulo 2008, 767 pp.

M. J. Arroba Conde - C. IZZI, Pastorale giudiziaria e prassi processuale nelle cause di nullità del matrimonio dopo la riforma operata con il Motu proprio Mitis Iudex Dominus Iesus, Cinisello Balsamo 2017, 320 pp.

P. Ballús, Las pericias psicológicas y psiquiátricas en los casos de nulidad matrimonial, in Curso de derecho matrimonial y procesal canónico para profesionales del foro 8, Salamanca 1989, 328.

P. Colpi, Precedenti dottrinali e giurisprudenziali del c. 1095, 2-3, in Monitor Ecclesiasticus 109, 1984, 517-539.

R. Genuin, Giusta, grave e gravissima causa nel diritto processuale canonico, Roma 1996.

S. Berlingó, Dalla perizia alla consulenza nel processo canonico, in Studi sul processo matrimoniale canonico, Padova 1991, 1-18. 
S. Gherro, Considerazioni canonistiche preliminari sulla perizia, in Perizie e periti nel processo matrimoniale canonico, Torino 1993, 15.

S. Gherro, Diritto matrimoniale canonico, Padova 1985, 58 ss.

S. Martín, La perizia nelle cause matrimoniali secondo la dottrina recente. In Perizie e periti nel processo matrimoniale canonico, Torino 1993, 130-131

Z. Grocholewski, Il giudice ecclesiastico di fronte alle perizie neuropsichiatriche e psicologiche, in Apollinaris 60, 1987, 183203.

Giovanni Paolo II, Allocuzione alla Rota Romana del 26.1.1984, in AAS 76, 1984, 648, n. 7;

Giovanni Paolo II, Allocuzione alla Rota Romana del 5.2.1987, in AAS 79, 1987, 1453-1459;

Giovanni Paolo II, Allocuzione alla Rota Romana del 25.1.1988, in AAS 80, 1988, 1178-1185.

Segnatura Apostolica nella sua dichiarazione del 16.6.1998, Prot. N. 28252/97 VT, in Periodica 87, 1988, 619-622.

T. Doran, Some thougts on experts, in Quaderni Studio Rotale 4, 1989, 10. 